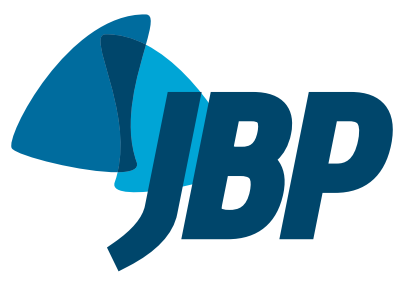

\title{
Pediatric Asthma Control and Communication Instrument: translation into Portuguese and cross-cultural adaptation for use in Brazil
}

\author{
Thayla Amorim Santino $0^{1, a}$, João Carlos Alchieri ${ }^{2, b}$, \\ Raquel Emanuele de França Mendes, ${ }^{1, c}$, Ada Cristina Jácome $e^{1, d}$, \\ Tácito Zaildo de Morais Santos ${ }^{1, e}$, Linda Kahn-D’Angelo ${ }^{3, f}$, \\ Cecilia M. Patino ${ }^{4,9}$, Karla Morganna Pereira Pinto de Mendonça ${ }^{1, h}$
}

1. Programa de Pós-Graduação em Fisioterapia, Universidade Federal do Rio Grande do Norte - UFRN - Natal (RN) Brasil.

2. Programa de Pós-Graduação em Ciências da Saúde, Universidade Federal do Rio Grande do Norte - UFRN - Natal (RN) Brasil.

3. Zuckerberg College of Health Sciences, University of Massachussets Lowell, Lowell (MA) USA

4. Department of Preventive Medicine, Keck School of Medicine, University of Southern California, Los Angeles (CA) USA.

a. (D) http://orcid.org/0000-0002-5514-762X

b. (D) http://orcid.org/0000-0002-4150-8519

c. (D) http://orcid.org/0000-0003-2226-5096

d. (D) http://orcid.org/0000-0002-5498-3108

e. (iD) http://orcid.org/0000-0002-9495-7078

f. (D) http://orcid.org/0000-0003-2050-5893

g. (D) http://orcid.org/0000-0001-5742-2157

h. (D) http://orcid.org/0000-0001-5734-3707

Submitted: 30 May 2018

Accepted: 10 January 2019

Study carried out in the Universidade

Federal do Rio Grande do Norte - UFRN -

Natal (RN) Brazil.

\begin{abstract}
Objective: To translate the Pediatric Asthma Control and Communication Instrument (PACCI) to Portuguese and adapt it for use in Brazil, ensuring the cultural validity of the content and semantic equivalence of the target version. Methods: The Brazilian Portuguese-language version of the PACCI was developed according to the most commonly used methodology, which included the following steps: translation; synthesis of the translation; review by the author of the original questionnaire; back-translation; synthesis of the back-translation; review by a native external researcher who is a native speaker of English; approval of the author of the original questionnaire; review by a specialist in Portuguese; review by a multidisciplinary committee of experts to determine the agreement of the items, considering the clarity of each and its appropriateness in the cultural context; cognitive debriefing; and development of the final version. The cognitive debriefing involved 31 parents/legal guardians of children 1-21 years of age with a clinical diagnosis of asthma, as defined by the Global Initiative for Asthma, with the objective of determining the comprehensibility and clarity of the items for the target population. Results: The multidisciplinary committee of experts indicated that the items on the questionnaire were clear and comprehensible, with kappa values above 0.61 , indicating substantial agreement. In the cognitive debriefing, the parents/legal guardians presented no difficulties in understanding any of the items (agreement $>0.90$ ); therefore, no further changes were needed.Conclusions: The translation and cross-cultural adaptation of the $\mathrm{PACCl}$ for use in Brazil were successful.
\end{abstract}

Keywords: Surveys and questionnaires; Translating; Asthma; Child; Adolescent.

\section{INTRODUCTION}

Asthma is a chronic lung disease with a global prevalence ranging from 1 to $18 \%$ of the population in different countries. ${ }^{(1)}$ In Brazil, asthma is a serious public health problem affecting mainly children and adolescents. ${ }^{(2)}$ The prevalence of asthma in the pediatric population in Brazil is above $20 \%$. $^{(2)}$

Asthma control is related to the occurrence of disease manifestations. ${ }^{(1,3)}$ The Global Initiative for Asthma (GINA) recommends that the clinical control evaluation be performed with the use of questionnaires. ${ }^{(1)}$ However, these should always provide a valid, reliable, accurate, and equivalent result interpretation. ${ }^{(4)}$

Some of the questionnaires available to evaluate the clinical control of asthma in children have already been validated for use in the Brazilian population, such as the
Childhood Asthma Control Test, ${ }^{(5)}$ the Asthma Control Test, ${ }^{(6)}$ the Asthma Control Questionnaire, ${ }^{(7)}$ and the Control of Allergic Rhinitis and Asthma Test for Children. (8) However, none of these questionnaires were developed to evaluate children under 4 years of age. In addition, these questionnaires ${ }^{(5-8)}$ were developed for use with restricted age groups. For this reason, it may be difficult to use these instruments as evaluation tools in studies involving participants from different age groups.

With that in mind, Okelo et al. ${ }^{(9)}$ developed the Pediatric Asthma Control and Communication Instrument (PACCI). The PACCI is a questionnaire developed for the multidimensional evaluation of the clinical control of asthma in children and adolescents between 1 and 21 years of age. It contains 12 questions, of which one is open-ended, aimed to improve communication between

Correspondence to:

Karla Morganna Pereira Pinto de Mendonça. Departamento de Fisioterapia, Universidade Federal do Rio Grande do Norte, Avenida Senador Salgado Filho, 3000 Caixa Postal 1524, Campus Universitário, Lagoa Nova, CEP 59072-970, Natal, RN, Brazil.

Tel.: 5584 3342-2022. E-mail: karlamorganna@hotmail.com

Financial support: Thayla Amorim Santino received a master's scholarship from the Coordenação de Aperfeiçoamento de Pessoal de Nive/ Superior (CAPES) -

Financial Code 001 
parents/guardians and health care professionals. The main purpose of the PACCI is to collect parents/ guardians' self-report via a straightforward instrument that is easy to use and understand, even for individuals with a low level of education. ${ }^{(9)}$

The PACCI is subdivided into five domains: direction (1 item), bother (1 item), risk (3 items), adherence ( 1 item), and control (5 items). ${ }^{(9)}$ The control domain can be scored in three ways: a sum of the items (from 0 to 19 points); problem index, in which each item is a dichotomous variable (from 0 to 5 points); and categories (controlled or uncontrolled), which is based on the color of the box checked on the right side of the instrument. The other domains receive categorical scores.

The objective of the present study was to translate the PACCI to Portuguese and make a cross-cultural adaptation for use in Brazil, aiming to fill in the gaps currently found in the toolbox of instruments available for the evaluation of the clinical control of pediatric asthma.

\section{METHODS}

The present study was approved by the Research Ethics Committee of the Federal University of Rio Grande do Norte (Process No. 1,808,185). All participants gave written informed consent and written informed assent. This is an exploratory methodological study based on recommendations proposed by several international studies. ${ }^{(10-13)}$

The process was composed of the following steps: 1) authorization from the author of the original questionnaire; 2) forward translation: the questionnaire was translated into Portuguese by two translators (1 and 2) working independently-both were native speakers of Portuguese and fluent in English, whereas one was a specialist in the field of knowledge addressed by the instrument and the other was not; 3) synthesis of the translations: consensus between translators 1 and 2 and the review committee (researchers conducting the study) on the translated versions with the aim of devising a single version; 4) report sent to the author of the original instrument for consideration and approval of steps 2 and 3 ; 5) back-translation: a translation of the synthesis of the first two translations into English by another two translators ( 3 and 4 ) who were native speakers of English and fluent in Portuguese and were blind to the original questionnaire; 6 ) synthesis of the back-translations: consensus between translators 3 and 4 and the review committee on the back-translations with the aim of devising a single version. In this step, an external researcher who was a native English speaker was asked to compare the final version of the back-translation into English with the original version and evaluate semantic equivalence; 7) report sent to the author of the original instrument for consideration and approval of steps 5 and 6 ; 8 ) review by a specialist in Portuguese who ensured an appropriate use of the standard language; 9) review by a multidisciplinary committee of experts to determine the agreement of the items, considering the clarity of each and its appropriateness in the cultural context; 10) cognitive debriefing: once the items were approved by the experts, a comprehension test of a pre-final version of the questionnaire was administered to the target population; and 11) report sent to the author of the original instrument for consideration and approval of the final version in Brazilian Portuguese. A diagram of the translation and cross-cultural adaptation process described above can be seen in Figure 1.

The semantic equivalence between the original and the translated version, as well as the appropriateness in the new cultural context, was achieved in the stages described previously. To ensure content validity, a multidisciplinary committee of experts was convened. This committee was composed of pediatricians and pulmonologists, physical therapists, researchers with experience in translation and cross-cultural adaptation of questionnaires, as well as lay individuals representing the target population (parents/guardians of children and adolescents with asthma), adding up to a total of nine members. To evaluate agreement, the Delphi method was used ${ }^{(14)}$ on SurveyMonkey ${ }^{\circledR}$ virtual platform. The selected experts evaluated each item and response options of the Portuguese version of the PACCI. The degree of agreement was calculated with the kappa test, considering the agreement values proposed by Landis and Koch. ${ }^{(15)}$

The cognitive debriefing was performed with a sample composed of 31 parents/guardians of children and adolescents between 1 and 21 years of age who had received a clinical diagnosis of asthma according to the GINA. (1) After clarification about the purpose and procedures of the study, the questionnaire was applied in the format of an interview. The interviewer read the questions, without any further explanation, repeating them when necessary; then the participants were asked about how clear and comprehensible each question was. If an item was unclear, the participant was encouraged to suggest possible changes to make it more comprehensible. If an item had a level of understanding below $90 \%$, $^{(16)}$ the previous steps of review by the multidisciplinary committee of experts and cognitive debriefing would be repeated for that item in order to guarantee a greater level of clarity.

The data were analyzed with IBM SPSS Statistics statistical package, version 22.0 (IBM Corporation, Armonk, NY, USA). The data analysis consisted of a descriptive analysis, with measures of absolute and relative frequency, central tendency, and dispersion. The kappa test was used to analyze the degree of agreement among the experts.

\section{RESULTS}

During the steps of translation and cross-cultural adaptation previously described, a few adjustments were deemed necessary to ensure clear understanding and adequate cross-cultural adaptation of the items 


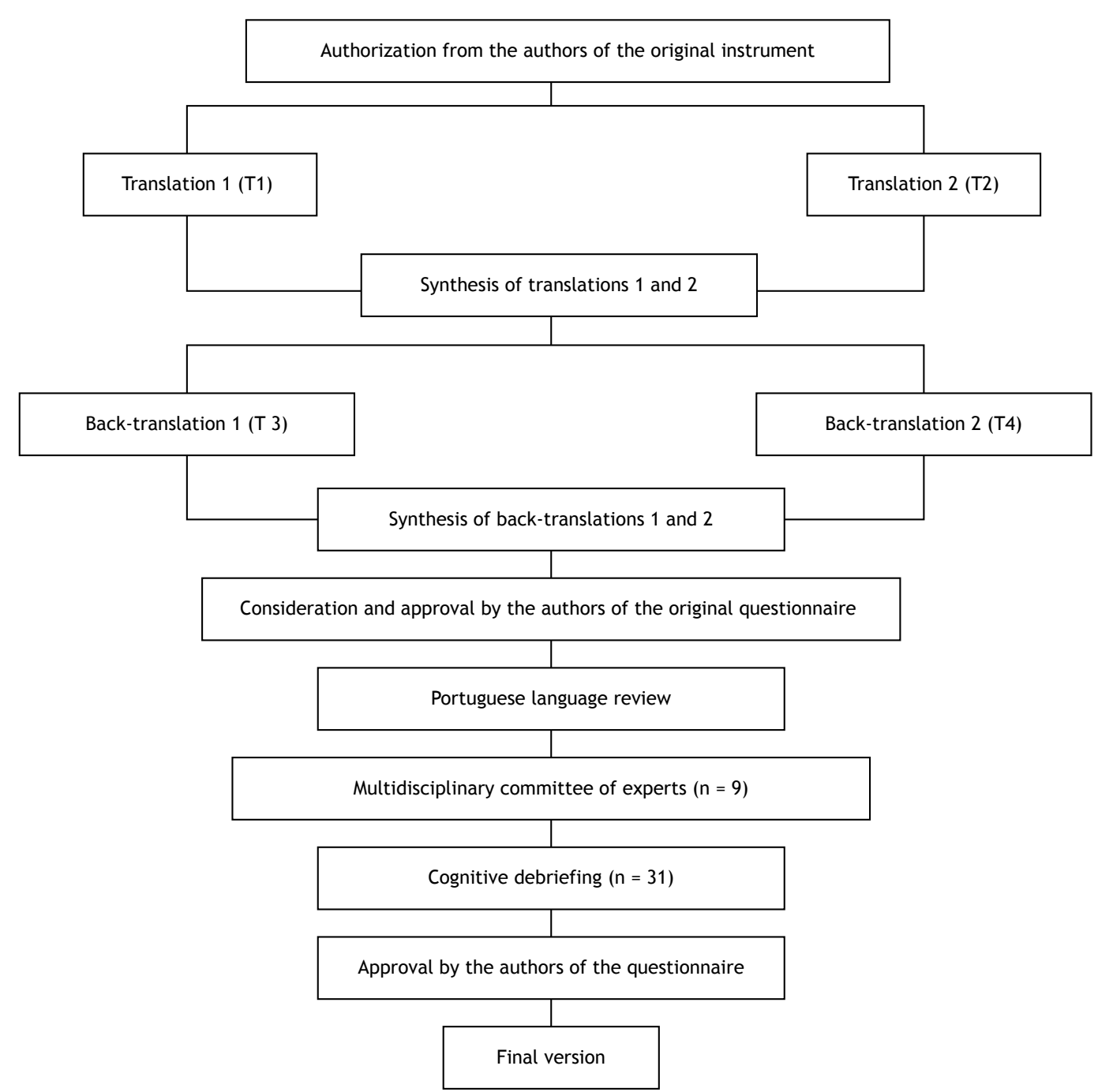

Figure 1. Steps of the translation and cross-cultural adaptation process of the Pediatric Asthma Control and Communication Instrument to Brazilian Portuguese.

and response options of the questionnaire. A report on the possible adjustments was submitted to the author of the original version after each step of the process. After approval from the author, the necessary changes were made. Through this process, it was possible to guarantee that the intention and meaning of the original items were fully preserved in the Portuguese version of the instrument.

Of the nine members of the multidisciplinary committee of experts, three were parents/guardians of children or adolescents with asthma, two were pediatricians, two were physical therapists specializing in respiratory physical therapy, one was a pulmonologist, and one was a researcher with methodological experience in translation and cross-cultural adaptation. As for the educational background of the health care professionals, three had a master's degree and another three had a Ph.D. They had between 7 and 31 years of professional experience. The parents/guardians who participated in the committee had different levels of educational attainment (high school, higher education, and postgraduate education).

Several sections of the original questionnaire use the term "your child"; however, instead of a literal translation, we chose to use the term "seu(sua) filho(a)" ["your son/daughter"]. This adjustment was deemed appropriate because the instrument was also intended for parents/guardians of adolescents.

Items 1 to 5 of the original instrument begin with the following sentence: "Since your child's last visit to this doctor's office, has your child:"; however, this has been adjusted to: "Desde a última consulta médica de seu(sua) filho(a), ele(a):" ["Since your son/daughter's last medical visit, he/she"], which made it simpler and more understandable in the new cultural context. In addition, the term "this doctor's office" could be inappropriate, depending on the place where the questionnaire was being applied. The term "hospitalized", used in item 4, was replaced by "internado" ["under inpatient 
care"], which is more widely used in Brazil and more appropriate in this context. In item 5 , the question "Used prednisone (Orapred, steroid pill, steroid liquid or steroid syrup) for asthma?" was changed to "Usou prednisona/prednisolona (comprimidos de corticoide ou cortisona, corticoide líquido, corticoide xarope ou injeção de corticoide) para sua asma?" ["Used prednisone/ prednisolone (corticosteroid or cortisone tablets, liquid corticosteroid, corticosteroid syrup, or corticosteroid injection) for his/her asthma?"]. Like the Portuguese version of the instrument for adults, the Asthma Control and Communication Instrument (ACCI), ${ }^{(17)}$ the following explanation was added to item 5: "Essa pergunta não se refere a sua bombinha de uso diário" ["This question does not refer to your daily use inhaler"]. The review committee proposed this adaptation be made with the purpose of making it clear that the item was not referring to the inhaled corticosteroids of daily use, but to the use of oral and injected corticosteroids used in periods of symptom exacerbation. In item 9 the expression "asthma attack" was replaced with "crises de asma" ["asthma crises"], since the original expression is not widely used by the Brazilian population.

Items $6,7,8$, and 9 of the original version provide examples to help or guide participants in completing the questionnaire. For a better adjustment to the context of the Brazilian population, the final version in Portuguese rephrases the examples in different ways: 1 ) item 6 refers to the daily medications most frequently used for asthma control in North America. However, some of these medications are not widely known or are unavailable for use in Brazil and were, therefore, replaced with more common ones. The following medications were mentioned originally "Advair, Asmanex, Budesonide, Dulera, Flovent, QVAR, Pulmicort, Singulair and Symbicort", while the translation mentions "Seretide spray e Diskus (Fluticasona e Salmeterol), Oximax (Mometasona), Budesonida, Formoterol, Fluticaps (Fluticasona), Clenil spray e A (beclometasona), Montelukast e Symbicort/ Alenia (Formoterol e Budesonida)" ["Seretide spray and Diskus (Fluticasone and Salmeterol), Oximax (Mometasone), Budesonide, Formoterol, Fluticaps (Fluticasone), Clenil spray and A (beclomethasone), Montelukast and Symbicort/Alenia (Formoterol and Budesonide)]; 2) item 7 contains examples of asthma symptoms that were mostly translated literally, except for the expressions "shortness of breath", "sputum (spit, mucous, phlegm when coughing)", and "wheezy or whistling sound in the chest". After consideration by the review committee, these symptoms were translated as "falta de ar" ["shortness of air"], "escarro (expectoração, muco, catarro ao tossir)" ["sputum (expectoration, mucus, catarrh when coughing)"], and "chiado ou sibilo (assobio) no peito" ["chest wheezing or hissing (whistling)"], respectively. 3) The original version of item 8 gives examples of the following forms or medicines for symptom relief: "Albuterol/ Proventil/Proair/Ventolin/Xopenex via Inhaler/Spray/ Pump or Machine/Nebulizer". In an attempt to simplify and mention medications or forms of administration that were more usual for the Brazilian population, the example in Portuguese says: "Salbutamol/Aerolin/ Berotec/Bombinha/Inalador/Nebulização" ["Salbutamol/ Aerolin/Berotec/Pump/Inhaler/Nebulizer"]. This format was also chosen because it bears similarity to the corresponding item of the Portuguese version of the questionnaire for adults, the ACCI. ${ }^{(18)}$

Adjustments were made to two response options only, in items 2 and 10 . Originally, item 2 presented the following response options: "Not bothered/Somewhat bothered/Very bothered". These were changed to "Nem um pouco incomodado/Um pouco incomodado/Muito incomodado" ["Not bothered at all/A little bothered/ Very bothered]". The response options of item 10 were "Not at all/Slightly/Moderately/Very much/Completely". These were changed to "Nem um pouco/Levemente/ Moderadamente/Muito/Completamente" ["Not at all/ Lightly/Moderately/Very/Completely"].

The analysis of agreement among the members of the multidisciplinary committee of experts showed that all items and response options of the questionnaire had kappa values above 0.61 , which indicates a high level of agreement. Therefore, there was no need for a second round of discussions.

During the cognitive debriefing of the pre-final version of the questionnaire, 31 parents/guardians were interviewed, of which 26 (83.9\%) were female. Their age ranged from 26 to 60 years. Most of the participants of the cognitive debriefing had children aged 2 to 15 years, most of whom were $5-11$ years old $(54.8 \%)$, eutrophic $(71.4 \%)$, with moderate asthma $(56.7 \%)$, which was partially controlled $(72.4 \%)$. The sample also included representatives with different levels of educational attainment, ranging from incomplete primary education to complete higher education, as well as representatives of various economic strata, according to the Brazilian Economic Classification Criteria ${ }^{(18)}$ of the Brazilian Association of Businesses and Research.

The evaluation of clarity and comprehension of the questionnaire was conducted by the parents/guardians who gave all items scores above $90 \%$ for both criteria. No comprehension difficulties were registered in any of the items and no suggestions were made, indicating no change was necessary.

\section{DISCUSSION}

The present study shows that the Brazilian Portuguese version of the PACCI and its cross-cultural adaptation were considered appropriate. All the instructions, response options, and items were considered clear and comprehensible by the target population.

Like other instruments that focus on quality of life, such as the Asthma Quality of Life Questionnaire ${ }^{(19)}$ and the Pediatric Asthma Quality of Life Questionnaire, ${ }^{(20)}$ the PACCI was developed in parallel with the adult version of the questionnaire, in this case the ACCI, (21) which evaluates clinical control of asthma in adults. 
The ACCI has already been translated and adapted for use in Brazil. ${ }^{(17)}$ Therefore, many relevant aspects reported during the cross-cultural adaptation of the $\mathrm{ACCI}^{(17)}$ that could also apply to the PACCI were taken into consideration, since both have similar structures and items.

In order to achieve an appropriate cross-cultural adaptation and to guarantee the construct was properly evaluated by the new population, the cognitive debriefing of the Brazilian Portuguese version of the PACCI was carried out with the participation of individuals from different educational and socioeconomic backgrounds, ensuring a better representation of the target population. There are currently four instruments available in Portuguese to evaluate the clinical control of pediatric asthma. ${ }^{(5,7,8,22)}$ However, this was the only study that included representatives of the different social strata and with different levels of education in an attempt to reflect the great diversity of the Brazilian population. The authors of the Brazilian version of the ACCI, ${ }^{(17)}$ which was originally developed to evaluate the clinical control of asthma in adults, also state, in an article about the process of translation of the instrument, they have included participants with different levels of education. However, they do not mention whether or not the Brazilian version of the ACCI took into consideration the socioeconomic diversity of the population for which the instrument was translated into and cross-culturally adapted. ${ }^{(17)}$

The PACCI differs from other instruments that focus specifically on the pediatric population and that are currently available in several respects. ${ }^{(5,7,8,22)}$ First, the PACCI is the only questionnaire developed specifically for the evaluation of the clinical control of asthma in children and adolescents across a wide age range, unlike the Childhood Asthma Control Test, for example, which applies to children between 4 and 11 years of age only. ${ }^{(5)}$ Second, the possibilities of score of the PACCI are differentiated. The three different ways to score the questionnaire and the possibility to use the GINA clinical control classification enable it to be adapted to different situations. ${ }^{(1)}$ Also, this instrument can facilitate the communication between physicians and patients because it contains an open-ended question that encourages parents/guardians to express their concerns about their child's asthma. ${ }^{(9)}$

Another characteristic that distinguishes the PACCI from the other questionnaires currently available to the Brazilian population is that it is based on parents/ guardians reports. ${ }^{(9)}$ The use of self-administered instruments in the pediatric population may result in answers of disputed validity and reliability due to the limitations of children's understanding. On the other hand, the self-report of adolescents provides more accurate information than that of parents/guardians. However, one should also consider the emotional and social aspects inherent to each stage of an adolescent's development. In this context, parent reports may be useful, especially in regards to symptoms and the impact of the disease. ${ }^{(23)}$
The GINA recommends that the assessment of asthma control be composed of two domains: control of manifestations and future risk. ${ }^{(1,24)}$ The other questionnaires currently available focus on symptom control only, ${ }^{(24)}$ whereas the PACCI contains questions related to future risk factors, which makes it more comprehensive than others in relation to these recommendations. The present study is also relevant since the process of translation and cross-cultural adaptation of instruments is the first step to make an instrument available for use in a population with another cultural and linguistic background. ${ }^{(11,13,25)}$ If an instrument is subject to incorrect or incomplete cross-cultural adaptation, misinterpretation of the results may occur either individually, within one country, or when making country comparisons. ${ }^{(26)}$

The methodology proposed in the present study has been widely used and can be considered a significant factor that leads to a more robust study. The profile of the translators included in the process and the inclusion of representatives of the target population in the multidisciplinary committee of experts should be considered in order to ensure a good semantic, conceptual and contextual equivalence between the versions. $^{(27-30)}$ However, previous studies about the translation and cross-cultural adaptation of specific questionnaires for the evaluation of the clinical control of pediatric asthma do not state whether or not these aspects were considered relevant. ${ }^{(5-7)}$

Such as previous studies of translation and cross-cultural adaptation of the questionnaires that evaluate the clinical control of asthma for the Brazilian population, ${ }^{(5,8)}$ the cognitive debriefing of the Brazilian version of the PACCI was not multicentric. Therefore, we would recommend that further studies be conducted in the future with the aim of comparing the rates of understanding and clarity of the instrument in other Brazilian regions, especially because Brazil has a large territory with distinct regional characteristics. Nevertheless, during the process of cross-cultural adaptation of the instrument, the use of regional terms was avoided in order to ensure the validity of the content of this version of the PACCI throughout the entire country. Another possible limitation of the present study was the absence of parents/guardians of children and adolescents of all ages within the proposed range (1-21 years of age). However, we believe this aspect did not impact the results of our study, since the respondents' understanding of the Brazilian version of the PACCI would certainly not be influenced by the age of their children.

In conclusion, we can state that the Brazilian Portuguese version of the PACCI was successfully adapted for use in Brazil (annex available on the JBP website: http://jornaldepneumologia.com.br/detalhe_anexo. asp?id=66). In addition, it is semantically equivalent to the original instrument and appropriate in the Brazilian context. The adapted version is also easy to understand and apply, regardless of the level of education and socioeconomic condition of the respondent. 


\section{REFERENCES}

1. Global Initiative for Asthma. Global Strategy For Asthma Management and Prevention. Bethesda: Global Initiative for Asthma; 2017.

2. Solé D, Camelo-Nunes IC, Wandalsen GF, Mallozi MC. Asthma in children and adolescents in Brazil: contribution of the International Study of Asthma and Allergies in Childhood (ISAAC). Rev Pau Pediatr. 2014;32(1):114-25. https://doi.org/10.1590/S010305822014000100018

3. British Thoracic Society; Scottish Intercollegiate Guidelines Network British guideline on the management of asthma. Edinburgh: Scottish Intercollegiate Guidelines Network; 2016.

4. Pernambuco L, Espelt A, Magalhães HV Junior, Lima KC Recommendations for elaboration, transcultural adaptation and validation process of tests in Speech, Hearing and Language Pathology. Codas. 2017;29(3):e20160217. https://doi. org/10.1590/2317-1782/20172016217

5. Oliveira SG, Sarria EE, Roncada C, Stein RT, Pitrez PM, Mattiello R. Validation of the Brazilian version of the childhood asthma contro test (c-ACT). Pediatr Pulmonol. 2016;51(4):358-63. https://doi. org/10.1002/ppul.23318

6. Roxo JP, Ponte EV, Ramos DC, Pimentel L, D'Oliveira Júnior A Cruz AA. Portuguese-language version of the Asthma Control Test validation for use in Brazil. J Bras Pneumol. 2010;36(2):159-66. https://doi.org/10.1590/S1806-37132010000200002

7. Leite M, Ponte EV, Petroni J, D'Oliveira Júnior A, Pizzichini E, Cruz AA. Evaluation of the asthma control questionnaire validated for use in Brazil. J Bras Pneumol. 2008;34(10):756-63. https://doi. org/10.1590/S1806-37132008001000002

8. Amaral R, Carneiro AC, Wandalsen G, Fonseca JA, Sole D. Control of Allergic Rhinitis and Asthma Test for Children (CARATKids) Validation in Brazil and cutoff values. Ann Allergy Asthma Immunol. 2017;118(5):551-556.e2. https://doi.org/10.1016/j.anai.2017.02.007

9. Okelo SO, Eakin MN, Patino CM, Teodoro AP, Bilderback $A L$, Thompson DA, et al. The pediatric Asthma Control and Communication Instrument asthma questionnaire: for use in diverse children of all ages. J Allergy Clin Immunol. 2013;132(1):55-62 https://doi.org/10.1016/j.jaci.2013.01.007

10. Guillemin F, Bombardier C, Beaton D. Cross-cultural adaptation of health-related quality of life measures: literature review and proposed guidelines. J Clin Epidemiol. 1993;46(12):1417-32. https:/ doi.org/10.1016/0895-4356(93)90142-N

11. Beaton DE, Bombardier C, Guillemin F, Ferraz MB. Guidelines for the process of cross-cultural adaptation of self-report measures. Spine (Phila Pa 1976). 2000;25(24):3186-91. https://doi. org/10.1097/00007632-200012150-00014

12. Mokkink LB, Terwee CB, Patrick DL, Alonso J, Stratford PW, Knol $\mathrm{DL}$, et al. The COSMIN study reached international consensus on taxonomy, terminology, and definitions of measurement properties for health-related patient-reported outcomes. J Clin Epidemiol. 2010;63(7):737-45. https://doi.org/10.1016/j.jclinepi.2010.02.006

13. Acquadro C, Conway K, Wolf B, Hareendran A, Mear I, Anfray C, et al. Development of a Standardized Classification System for the Translation of Patient-Reported Outcome (PRO) Measures Brief Measure of Psychological Well-Being. Patient Rep Outcomes Newsl. 2008;39:5-7

14. Powell C. The Delphi Technique: myths and realities. J Adv Nurs. 2003;41(4):376-82 $\quad$ https://doi.org/10.1046/.13652648.2003.02537.x

15. Landis JR, Koch GG. The measurement of observer agreement for categorical data. Biometrics. 1977;33(1):159-74. https://doi. org/10.2307/2529310

16. Reichenheim ME, Moraes CL. Operationalizing the cross-cultural adaptation of epidemiological measurement instruments [Article in
Portuguese]. Rev Saude Publica. 2007;41(4):665-73.

17. Tavares MGS, Brümmer CF, Nicolau GV, Melo JT Jr, Nazário NO, Steidle LJM, et al. Translation and cultural adaptation of a specific instrument for measuring asthma control and asthma status: the Asthma Control and Communication Instrument. J Bras Pneumol. 2017;43(4):264-9. https://doi.org/10.1590/s180637562016000000182

18. Kamakura W, Mazzon JA. Socioeconomic stratification criteria and classification tools in Brazil [Article in Portuguese]. Rev Adm Empres. 2016;56(1):55-70. https://doi.org/10.1590/S0034-759020160106

19. Juniper EF, Guyatt GH, Epstein RS, Ferrie PJ, Jaeschke R, Hiller TK Evaluation of impairment of health related quality of life in asthma: development of a questionnaire for use in clinical trials. Thorax. 1992;47(2):76-83. https://doi.org/10.1136/thx.47.2.76

20. La Scala CS, Naspitz CK, Solé D. Adaptation and validation of the Pediatric Asthma Quality of Life Questionnaire (PAQLQ) in Brazilian asthmatic children and adolescents. J Pediatr (Rio J). 2005;81(1):5460. https://doi.org/10.2223/1283

21. Patino CM, Okelo SO, Rand CS, Riekert KA, Krishnan JA, Thompson $K$, et al. The Asthma Control and Communication Instrument: a clinical tool developed for ethnically diverse populations. J Allergy Clin Immunol. 2008;122(5):936-43.e6. https://doi.org/10.1016/j. jaci.2008.08.027

22. Tavares MG, Pizzichini MM, Steidle LJ, Nazário NO, Rocha CC, Perraro $\mathrm{MC}$, et al. The Asthma Control Scoring System: translation and crosscultural adaptation for use in Brazil. J Bras Pneumol. 2010;36(6):68392. https://doi.org/10.1590/S1806-37132010000600004

23. Matza LS, Patrick DL, Riley AW, Alexander JJ, Raimil L, Pheil AM et al. Pediatric patient-reported outcome instruments for research to support medical product labeling: report of the ISPOR PRO good research practices for the assessment of children and adolescents task force. Value Health. 2013;16(4):461-79. https://doi.org/10.1016/j. jval.2013.04.004

24. Reddel HK, Levy ML; Global Initiative for Asthma Scientific Committee and Dissemination and Implementation Committee. The GINA asthma strategy report: What's new for primary care? NPJ Prim Care Respir Med. 2015;25:15050. https://doi.org/10.1038/ npjpcrm.2015.50

25. Acquadro C, Bayles A, Juniper E. Translating patient-reported outcome measures: a multi-step process is essential. J Bras Pneumol. 2014;40(3):211-2. https://doi.org/10.1590/S180637132014000300002

26. García-Gavín J, Pérez-Pérez L, Tinazzi I, Vidal D, McGonagle D Spanish Cultural Adaptation of the Questionnaire Early Arthritis for Psoriatic Patients. Actas Dermosifiliogr. 2017;108(10):924-930. https://doi.org/10.1016/j.ad.2017.06.006

27. Ramada-Rodilla JM, Serra-Pujadas C, Delclós-Clanchet GL. Crosscultural adaptation and health questionnaires validation: revision and methodological recommendations [Article in Spanish]. Salud Publica Mex. 2013;55(1):57-66. https://doi.org/10.1590/S003636342013000100009

28. Sousa VD, Rojjanasrirat W. Translation, adaptation and validation of instruments or scales for use in cross-cultural health care research: a clear and user-friendly guideline. J Eval Clin Pract. 2011;17(2):268-74. https://doi.org/10.1111/j.1365-2753.2010.01434.x

29. Victal ML, Lopes MH, D'Ancona CA. Adaptation of the O'Leary-Sant and the PUF for the diagnosis of interstitial cystitis for the Brazilian culture [Article in Portuguese]. Rev Esc Enferm USP. 2013;47(2):312 9. https://doi.org/10.1590/S0080-62342013000200006

30. Jensen R, Cruz Dde A, Tesoro MG, Lopes MH. Translation and cultural adaptation for Brazil of the Developing Nurses' Thinking model. Rev Lat Am Enfermagem. 2014;22(2):197-203. https://doi. org/10.1590/0104-1169.3232.2402 